DeAr Sirs

I wish to comment on some of the extremely important issues raised by $\mathrm{Dr}$ Tufnell in her letter and to offer further information about the endeavours made to secure media coverage for the meeting of the European Society of Child and Adolescent Psychiatry (ESCAP) in London in September 1991.

Dr Tufnell suggests that psychiatrists should adopt public relations strategies and harness the media to make purchasers, managers, our patients and the public more effectively aware of the scope and value of what psychiatry and psychiatrists have to offer. I agree entirely.

The Royal College of Psychiatrists has a small but active, and increasingly effective, Public Education Department which has adopted the strategic awareness which Dr Tufnell espouses.

The ESCAP meeting was administratively supported in a major way by the staff and the Departments of the Royal College of Psychiatrists. This included the Public Education Department. Both the College staff member who runs this Department and I, a professional member of its staff, were involved in providing this support.

Prior to the conference a large number of media people were offered details of the press conferences which were held twice daily throughout the conference. The large volume of publicity which followed the opening speech given by the Princess of Wales was not surprising and this did indeed give the Conference a high profile. It is true that the press conferences were sparsely attended. However, the College Public Education staff did create a considerable number of informal contacts between individual speakers and members of the press. Dr Tufnell points out that the BPS has worked very hard over the last 15 years to create its successful public image and that need for cultivation over an extended period is endorsed by the experiences of the College Public Education Department.

Perhaps this has a bearing on the apparently restricted volume of press coverage which resulted from the ESCAP conference. ESCAP meets at a different venue in Europe once every four years. I was therefore not unduly surprised to find that the immediate press coverage was thin but, nonetheless, believe that the exercise of providing the Public Education Department's support for the ESCAP meeting was worthwhile. The individual contacts made between the press and psychiatrists may yet yield positive results and contribute to positive impressions of the specialty.

In short, the College has got the message! The Public Education Department is working hard to challenge stigma and create a positive image of psychiatry. Its members have embarked upon the task of encouraging College Divisions and Sections to create relationships with the media through their Public
Education Officers. The support of more members with Dr Tufnell's positive attitude to public relations would be very welcome.

Consultant Child and Adolescent Psychiatrist

Member of the Public Education Committee of

The Royal College of Psychiatrists

\section{Harassment by patients}

\section{DeAR Sirs}

A number of clinical syndromes have been recognised in which an individual becomes unduly attracted to, or hostile towards, their medical attendants and may subject them to unwarranted attention which, at times, amounts to serious harassment. There is little information on the frequency of such harassment, the remedies which can be applied and the attitudes of colleagues and employing authorities towards the victim.

In order to offer advice to psychiatrists and employing authorities, the College have asked me to collate available information and prepare a report. I would be very grateful if psychiatrists aware of such incidents, now or in the past, would write to me in confidence providing as much information as is possible about individual instances.

Details of clinical diagnosis, the use of the Mental Health Act or other legal remedies and any general advice would be useful. It would be of particular interest to hear of action by or support from employing authorities.

University of Leicester

S. BRANDON

School of Medicine

Leicester Royal Infirmary

Leicester LE2 $7 L X$

\section{Manic depression psychosis}

\section{DeAR Sirs}

The College's Patients' Liaison Group has received a letter from a man suffering from manic depression who states that he is occasionally in hospital suffering from delusions of grandeur. However on his Lithium Tests form he finds the diagnosis of 'Manic Depressive Psychosis' even when discharged and long out of hospital. He points out that he is psychotic for only a few weeks every year or two and asks: "Surely psychosis is a state of mind, not a potential state of mind, nor a condition of the mind that might give rise to a psychotic episode? What I want to know is why I am called a madman, permanently, when I am only a part-time madman?"

The Patients' Liaison Committee felt that he made a very cogent point and that the use of the term 